\title{
Aprendizaje servicio como herramienta metodológica en la educación superior
}

\section{Gema Santander}

Universidad de Santo Tomás, Chile.

\section{Resumen}

El presente testimonio pretende motivar a docentes de educación superior a realizar un análisis de las asignaturas que están dictando en este momento o las que tienen en planificación y vean si son factibles de decretarlas como asignaturas con metodología de aprendizaje servicio. Se entrega una propuesta de pasos a seguir que puede servir como primera orientación en relación al tema, que de ser real, aportará en la demostración de la responsabilidad social universitaria.

\section{Palabras clave}

Aprendizaje servicio, responsabilidad social, metodología.

Fecha de recepción: 22/IX/2016

Fecha de aceptación: 1/IV/2017 


\title{
Service learning as a methodological tool in higher education
}

\begin{abstract}
The present testimony aims to motivate higher education teachers to perform an analysis of the subjects who are dictating at this time or which have in planning and see if they are feasible to enact them as subjects with service learning methodology. It gives a proposal of steps to follow that can serve as a first orientation in relation to the subject, which if real, will contribute to the demonstration of university social responsibility.
\end{abstract}

\section{Keywords}

Service learning, social responsibility, methodology. 


\section{Presentación}

El aprendizaje servicio se concibe como una metodología de enseñanza aprendizaje y como una estrategia para demostrar la responsabilidad social universitaria.

La definición que usamos en Chile en la Red de Aprendizaje y Servicio dice que "Aprendizaje servicio es un enfoque pedagógico de enseñanza-aprendizaje aplicado en cursos, prácticas y tesis, en donde se resuelven problemáticas sociales reales mediante un servicio de calidad, en el que de manera integrada y colaborativa los tres actores presentes en el proceso (docentes, estudiantes y socios comunitarios) se vinculan y trabajan en conjunto".

En base a esto se puede concluir que muchas de las actividades que están decretadas en las mallas curriculares de diferentes carreras profesionales corresponden a esta metodología.

Para verificar el punto anterior se propone a los docentes de Enfermería que analicen sus asignaturas e identifiquen si estas contienen temas y actividades que estén dando respuesta a las problemáticas sociales que existen en todas partes. La idea es que en este análisis contrasten los contenidos con las etapas que debe considerar esta metodología, de manera que si son coincidentes podemos declarar como tal esta metodología.

A continuación se identifican las etapas a seguir:

1. Identificar si la programación tiene declarado asignatura teórico-práctica, si es así, tiene una alta probabilidad de insertar aprendizaje servicio.

2. Si en la asignatura se requiere desarrollar competencias como trabajo en equipo, desarrollo de identidad, desarrollo de afectividad, sentido de pertenencia, comportamientos pro sociales, incremento de autoestima, desarrollo de la empatía, de habilidades de comunicación, creatividad, iniciativa, desarrollo de pensamiento crítico, capacidad de generar consensos, respeto por la diversidad, entre otras, la metodología ApS es muy apropiada.

3. En el ítem Metodología de la asignatura, declarar aprendizaje servicio.

4. Realizar un listado con posibles acciones o actividades que se puedan desarrollar con grupos comunitarios idealmente vulnerables, teniendo presentes los objetivos de aprendizaje y las competencias que se desean lograr en los estudiantes, precisando lo que ellos son capaces de realizar en la comunidad.

5. En forma simultánea o con anticipación se debe conocer posibles grupos comunitarios, que hayan manifestado necesidades reales, o se debe contar con algún diagnostico donde esté determinada objetivamente la necesidad de esa comunidad, necesidad que sea factible de abordar con los estudiantes. Si no se cuenta con este antecedente, se debe ubicar algún grupo comunitario vulnerable y se debe iniciar el trabajo docente estudiantil con el diagnostico participativo de 
necesidades sentidas y reales de esa población.

\section{Programar reuniones participativas} con los socios comunitarios para generar un plan de trabajo conjunto, basado en la realidad de ambas partes.

7. Es muy pertinente conocer las expectativas de los estudiantes y de los integrantes de la comunidad con que se trabajará, con el fin de no crear falsas expectativas.

8. Se elabora el proyecto por escrito. Se debe decidir: nombre del proyecto, participantes, objetivos, actividades propuestas, calendarización, determinación de responsabilidades, determinación productos, formas de evaluar, formas de evidenciar las actividades (cuadernos de campo, bitácoras, portafolios, pautas de observación, fotografías, videos), como se realizará el cierre del proyecto.

9. Desarrollo del proyecto, respetando calendarización, responsables, evidencias, productos, reflexión, pre evaluación, imprevistos, adecuaciones.

10. Término del proyecto, se concluye con el balance donde se compara lo propuesto con lo logrado.

11. Difusión de los resultados por medio de reuniones, exposiciones, entrega de documentos, entrega de productos tangibles, colocar en medios de comunicación social, participar en eventos científicos, publicar, proponer un proyecto de investigación.

12. Además se debe realizar una actividad formal de cierre, con la entrega de algún reconocimiento especial o certificados.

13. Una vez evaluado se debe decidir si es pertinente la continuidad del trabajo realizado, si se deben sumar otros participantes debido a que surgieron nuevas demandas o propuestas.

En relación con las evaluaciones, es recomendable realizar evaluación formativa verbal después de cada reunión, encuentro y actividad realizada, esto permite ir haciendo las adecuaciones pertinentes y da el espacio para la reflexión, condición fundamental de esta metodología. Se debe reflexionar sobre el proceso, los resultados de aprendizaje y los beneficios para todos los participantes (docentes, estudiantes, participantes de la comunidad).

En evaluación sumativa se pueden incorporar rúbricas y pautas aplicadas a los productos considerados dentro del proyecto (portafolio, documento del proyecto, cuaderno de campo, registros u otro sistema conocido), los estudiantes (autoevaluaciones y evaluaciones de los pares), al socio comunitario (donde evalúa desde su mirada el trabajo realizado y el comportamiento de los estudiantes).

\section{Argumentación}

En todas las carreras de educación superior es muy importante demostrar la responsabilidad social universitaria. La metodología aprendizaje servicio es una forma operativa de demostrarla, ya que no solo permite realizar una práctica comunitaria, sino que además 
se resuelve una necesidad sentida de una población, que de no ser por este servicio estaría postergada por un tiempo indeterminado.

En seguno lugar, el tema de contar con campos para desarrollar las competencias de los estudiantes de diversas carreras y muy especialmente de las carreras del área de la salud, es cada vez más difícil, sobre todo en las localidades donde hay muchas casas de educación superior, y esta es una forma de contar con la oportunidad de desarrollar las competencias del saber, del ser y del hacer. Lo que se aprende haciendo nunca se olvida.

En tercer lugar, es una forma importante de demostrar vinculación con el medio de la universidad, centro de formación técnica o instituto profesional al difundir a nivel comunitario el aporte real y comprometido que hacen estudiantes y docentes.

En cuarto lugar, se producen bases de datos muy valiosas para investigaciones en distintas áreas que pueden desarrollar los estudiantes o los docentes.

Finalmente, más que aportes financieros se requiere de una muy buena gestión de recursos para llevar a cabo estos proyectos. Se produce un intercambio muy enriquecedor de lo que aporta la comunidad con lo que aporta la universidad.

\section{Conclusión}

Por tener formación en esta área, por haber vivenciado los beneficios, me atrevo a motivar a docentes no solo del área de la salud, a sumarse a esta experiencia. Es muy motivador por ver la evolución y metamorfósis que se produce en los estudiantes y en las comunidades con las que se trabaja. No son intervenciones, son interacciones ya que se trabaja de ambas partes y todos se benefician.

Para muchas carreras no es difícil sumarse a esto ya que de alguna manera ya se realiza sin saber que se está aplicando esta metodología. Tal vez solo falta cumplir con el incremento de la reflexión y de sistematizar las experiencias por medio de las evaluaciones. 